\title{
USE OF BENDING TESTS AND VISUAL INSPECTION FOR MULTI-SCALE EXPERIMENTAL EVALUATION OF CHESTNUT TIMBER BEAMS STIFFNESS
}

\author{
Hélder S. SOUSA, Jorge M. BRANCO, Paulo B. LOURENÇO \\ Department of Civil Engineering, ISISE, University of Minho, Portugal
}

Received 21 Feb 2013; accepted 30 Jul 2013

\begin{abstract}
The assessment of existing timber structures requires the determination of the mechanical properties of the individual timber members, which is often obtained by visual grading combined with information of small clear wood specimens. The purpose of this work is to present the results obtained in a multi-scale experimental evaluation of 20 old chestnut (Castanea sativa Mill.) beams, aimed at defining the correlations between bending modulus of elasticity (MOE) in different scales of timber members in combination with visual grading. The results of bending tests, according to EN 408:2010 (2010), were statistically analyzed to obtain correlations of bending MOE between and within different scales size. The results of visual inspection according to UNI 11119:2004 (2004) regarding the presence and distribution of defects were considered for variation analysis of MOE, evidencing a significant variance between samples of different visual strength grades. Strong correlations within the same phase (coefficient of determination $r^{2}$ from 0.82 to 0.89 ) and moderate to high correlations for different phases $\left(r^{2}\right.$ from 0.68 to 0.71$)$ were found for bending MOE. Cumulative distribution functions for global MOE remained similar throughout the experimental phases. Moreover, percentage of segments attributed to a specific visual grade is given for each member and compared between scales.
\end{abstract}

Keywords: chestnut beams, modulus of elasticity in bending, visual grading, properties correlation, bending stiffness variation.

\section{Introduction}

The assessment of existing timber structures requires the determination of the mechanical properties of the individual timber members and joints. Despite the significant efforts in the development of non-destructive testing, either at local or global levels, the true strength of a timber member can only be directly determined in a destructive test, which is unacceptable. Therefore, strength grading of existing timber members is made by indirect prediction of the mechanical properties using visual inspection and non-destructive testing.

Visual inspection is subjective and may be even inaccurate as evidenced by Huber et al. (1985) for grading red oak lumber, when inspectors achieved only $68 \%$ of the expected result with respect to recognizing, locating and identifying defects. To overcome these obstacles and to unify criteria in Europe, general guidelines for visual grading were issued in the European standard EN 518:1997 (1997), afterwards superseded by EN 140811:2005 (2005), by specifying the minimum requirements for visual and machine graded structural timber with rectangular cross section. Subsequent national standards were developed in order to establish strength classes for local wood species, whereas assignment of species and visual grades from national standards to strength classes is provided by EN 1912:2012 (2012). A comparison between visual strength grading standards for different countries has been addressed (e.g. Almazán et al. 2008; Muñoz et al. 2011). The need to relate the presence of defects to the stress distribution in a member has been pointed out by the Italian standard UNI 11119:2004 (2004). According to this standard, a single strength class may be assigned to an individual member once the critical areas are identified. However, as mentioned by Branco et al. (2010), if the visual grading is based on the evaluation of local defects but the result is the assignment of a specific strength class to the entire timber element, this leads to a loss in evaluating local defects. Overall, the result of visual strength grading is the attribution of nominal values or allowable stress levels for indirect prediction of key properties which, due to its correlation to other properties, allow for the mechanical characterization of the material. One key property for the prediction of strength of timber elements is its bending modulus of elasticity (MOE). Indeed, stiffness, usually expressed as a modulus of elasticity, is the best predictor of strength, with

Corresponding author: Hélder S. Sousa

E-mail:hssousa@civil.uminho.pt 
a coefficient of determination $r^{2}$ ranging from 0.51 to 0.73 according to several studies compiled in Thelandersson and Larsen (2003).

Gloss (1986) provides even better results and reports that the coefficient of correlation between MOE and bending, tensile or compressive strength ranges from 0.7 to 0.8 . Also, MOE was found to permit better correlations to non-destructive testing than bending strength (e.g. Teder et al. 2012). The relation between strength and MOE can, however, be affected by the presence of significant local defects, and a decrease of the MOE is also expected when decay is present. In Burley et al. (2004) a coefficient of variation $(\mathrm{CoV})$ between 9 and $23 \%$ was found for MOE in bending for small clear wood specimens. Nevertheless, it must be noted that the variation is lower for small clear specimens and highly depends on the reliability of the source of information. Also, the correlations between properties are higher for small-clear specimens and lower for large members (Kasal 2010).

In this context, the purpose of the present work is to address the correlation of bending MOE in different scales size of a timber element. Also, it is intended to investigate the interest of visual inspection for variation analysis of MOE between and within different scales size, regarding the presence of defects and its distribution. For these purposes, a multi-phase experimental campaign, conducted to twenty old chestnut beams, and its results are presented and analyzed.

\section{Experimental campaign and database}

\subsection{Materials and test sequence}

The more than a century old chestnut (Castanea sativa Mill.) timber beams were taken from a building in the city of Braga, Northern Portugal, where they served as simply supported structural floor beams, in both endings, by granite masonry walls. The length of the elements varied between $4 \mathrm{~m}$ and $6 \mathrm{~m}$ with a mean value of $5.32 \mathrm{~m}$ and a $\mathrm{CoV}$ of $11.8 \%$. The average values for the nominal cross section dimensions were $18.0 \mathrm{~cm}(\mathrm{CoV}=3.1 \%)$ for height and $13.0 \mathrm{~cm}(\mathrm{CoV}=6.0 \%)$ for width. Even if the variation in the nominal cross section dimensions within each element was low, significant wane was found. This wane was mainly consequence of the initial sawing process rather than from deterioration (elements still presented sharp edges) and did not pose problems to the existing connections to other structural elements. The floor itself consisted in a traditional solution with wooden planks nailed to the top surface of the beams. These beams were selected since they presented a state of conservation commonly found for existing timber structures. With this choice, the results from each testing phase may be considered and compared to this state of conservation, thus being useful to allocate indicative mechanical properties to other existing timber elements with similar characteristics and visual grading.

The testing phase sequence, with three different phases regarding the size and characteristics of the timber elements, is presented in Figure 1. From one to the next phase, the timber elements were sawn into smaller sizes in order to isolate the influence of defects and better define their correlation to a more precise distribution of bending MOE along the length and height of the timber element.

After being removed from the construction site, the beams were marked (A to T) and visually graded on each $40 \mathrm{~cm}$ segment using UNI 11119:2004 (2004), corresponding to Phase 1 of the experimental campaign. After the initial visual inspection, the external degradation (presence of decay by fungi and/or xylophages attack) was removed and the old beams were cut to $7 \times 15 \times 300 \mathrm{~cm}^{3}$ sawn beams. Phase 2 of the experimental campaign began by marking 7 consecutive

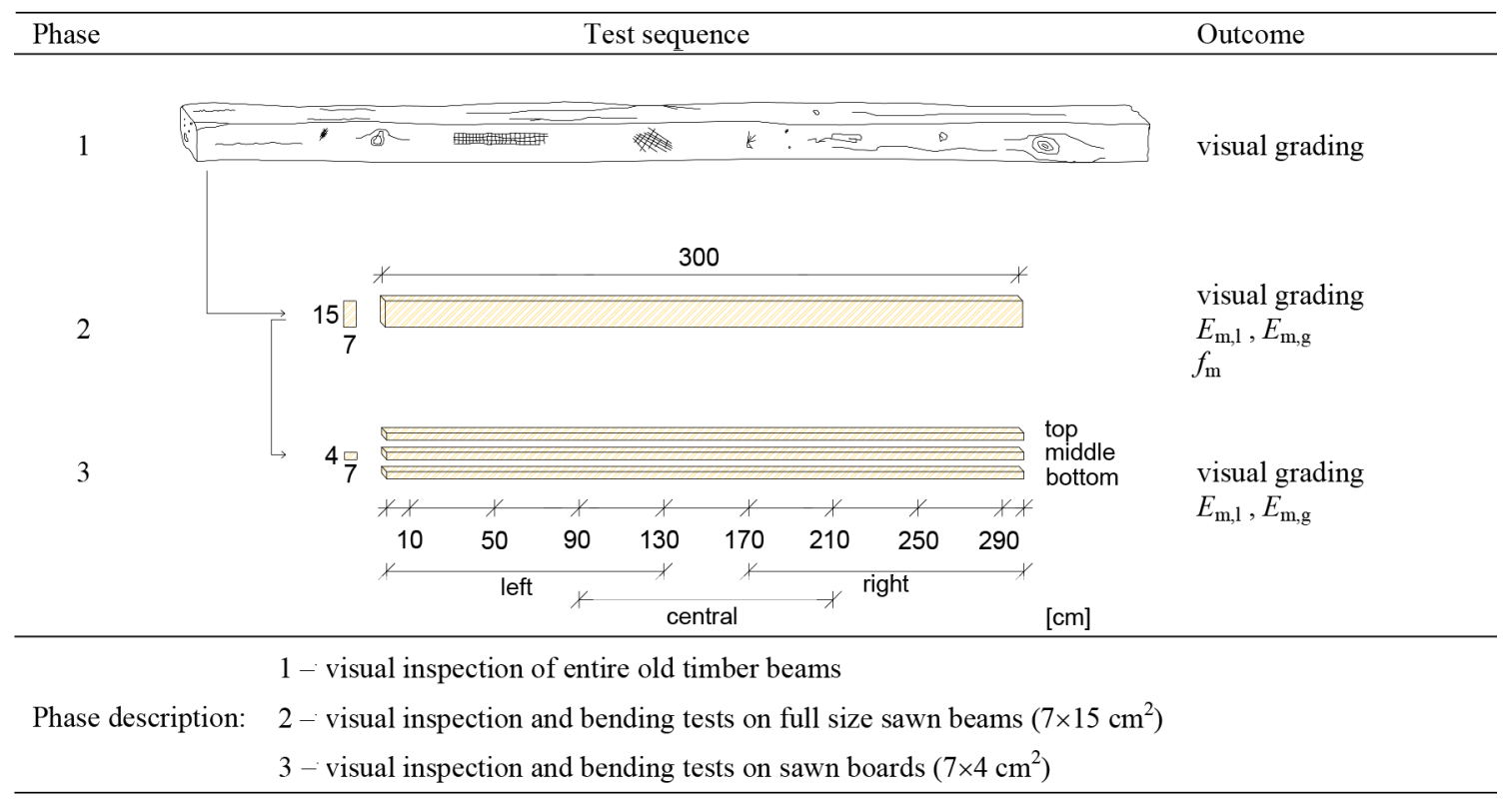

Fig. 1. Testing phases and results obtained for each sample 
segments of $40 \mathrm{~cm}$ on each sawn beam. After being marked, each sawn beam segment was visually graded with consideration to the presence, extent and typology of the found defects. Then, 4-point bending tests, according to EN 408:2010 (2010), were made to each beam (4 beams until failure, beams H, L, P and T, and 16 only in elastic range), obtaining local $\left(E_{\mathrm{m}, 1}\right)$ and global $\left(E_{\mathrm{m}, \mathrm{g}}\right)$ modulus of elasticity in bending. Finally, the beams that were not taken to failure were sawn into 3 boards each with $7 \times 4 \times 300 \mathrm{~cm}^{3}$, obtaining a total of 48 boards to be analyzed in Phase 3 . Each board was visually inspected and graded on each $40 \mathrm{~cm}$ segment. All segments were subsequently subjected to a 4-point bending test in elastic range to assess the variation of MOE along the element's length, thus obtaining a total of 336 tests.

\subsection{Testing methodology}

As the timber beams were removed from the building and visually inspected in laboratory, it was possible to assess all the faces of the beams, which often is not possible in an on site evaluation. The timber elements, in the different test phases, were visually inspected and graded, accordingly to the Italian norm UNI 11119:2004 (2004), on each $40 \mathrm{~cm}$ segment. This norm establishes objectives, procedures and requirements for the diagnosis of the state of conservation and estimates the mechanical properties (strength and stiffness) for structural wood elements present in cultural heritage buildings. Its methodological approach consists in visual inspection complemented by non-destructive tests. For strength grading of a single element, this norm considers three classes (I, II and III) regarding on site diagnosis. The wood element is considered to be from a given class if it fulfils all the imposed requirements (Table 1) and for each separate class, nominal strength and stiffness values are given. In this study, when the imposed requirements were not fulfilled for any of the mentioned classes, the segment was graded as non-classifiable (NC). All defects present on each face were therefore identified, measured and mapped. However, in Phase 1, since timber elements were placed in the structure already with the wane that resulted from the initial sawing process, a visual strength grading was considered without the limitation of the wane. This procedure is adequate if the residual cross section without the wane is considered and, also, because the beams were only sawn for the faces that would be in contact with other elements, leaving the remaining faces round.

After the visual inspection, bending tests were made according to EN 408:2010 (2010). The test specimen length, $l$, and the distance between the supports and the loading positions, $a$, are proportional to the depth of the cross section, $h$. For bending, this norm suggests the determination of a local modulus of elasticity, $E_{\mathrm{m}, \mathrm{l}}$, and of a global modulus of elasticity, $E_{\mathrm{m}, \mathrm{g}}$. The $E_{\mathrm{m}, 1}$ is measured in a central distance, while the $E_{\mathrm{m}, \mathrm{g}}$ is measured along the full span of the beam between supports. The MOE values are calculated according to Eqns (1) and (2):

$$
\begin{gathered}
E_{\mathrm{m}, \mathrm{l}}=\frac{a \cdot l_{1}^{2} \cdot\left(F_{2}-F_{1}\right)}{16 \cdot I \cdot\left(w_{2}-w_{1}\right)}=\frac{a \cdot l_{1}^{2} \cdot \Delta F}{16 \cdot I \cdot \Delta w} ; \\
E_{\mathrm{m}, \mathrm{g}}=\frac{3 \cdot a \cdot l^{2}-4 \cdot a^{3}}{2 \cdot b \cdot h^{3} \cdot\left(2 \cdot \frac{\Delta w}{\Delta F}-\frac{6 \cdot a}{5 \cdot G \cdot b \cdot h}\right)},
\end{gathered}
$$

where: $b$ is the width of the cross section (mm); $h$ is the height of the cross section $(\mathrm{mm}) ; \Delta F$ is an increment of load $(\mathrm{N}) ; \Delta w$ is the increment of deformation $(\mathrm{mm})$ corresponding to $\Delta F$; $a$ is the distance between a loading position and the nearest support $(\mathrm{mm}) ; l$ is the span between supports $(\mathrm{mm}) ; l_{1}$ is the gauge length $(\mathrm{mm})$ for the determination of $E_{\mathrm{m}, 1} ; I$ is the inertia moment $\left(\mathrm{mm}^{4}\right)$; and $G$ is the shear modulus $\left(\mathrm{N} / \mathrm{mm}^{2}\right)$.

It is noted that $E_{\mathrm{m}, 1}$ is measured in a region with null shear stress and constant bending moment, whereas

Table 1. Grading rules for structural elements in an onsite diagnosis (UNI 11119:2004)

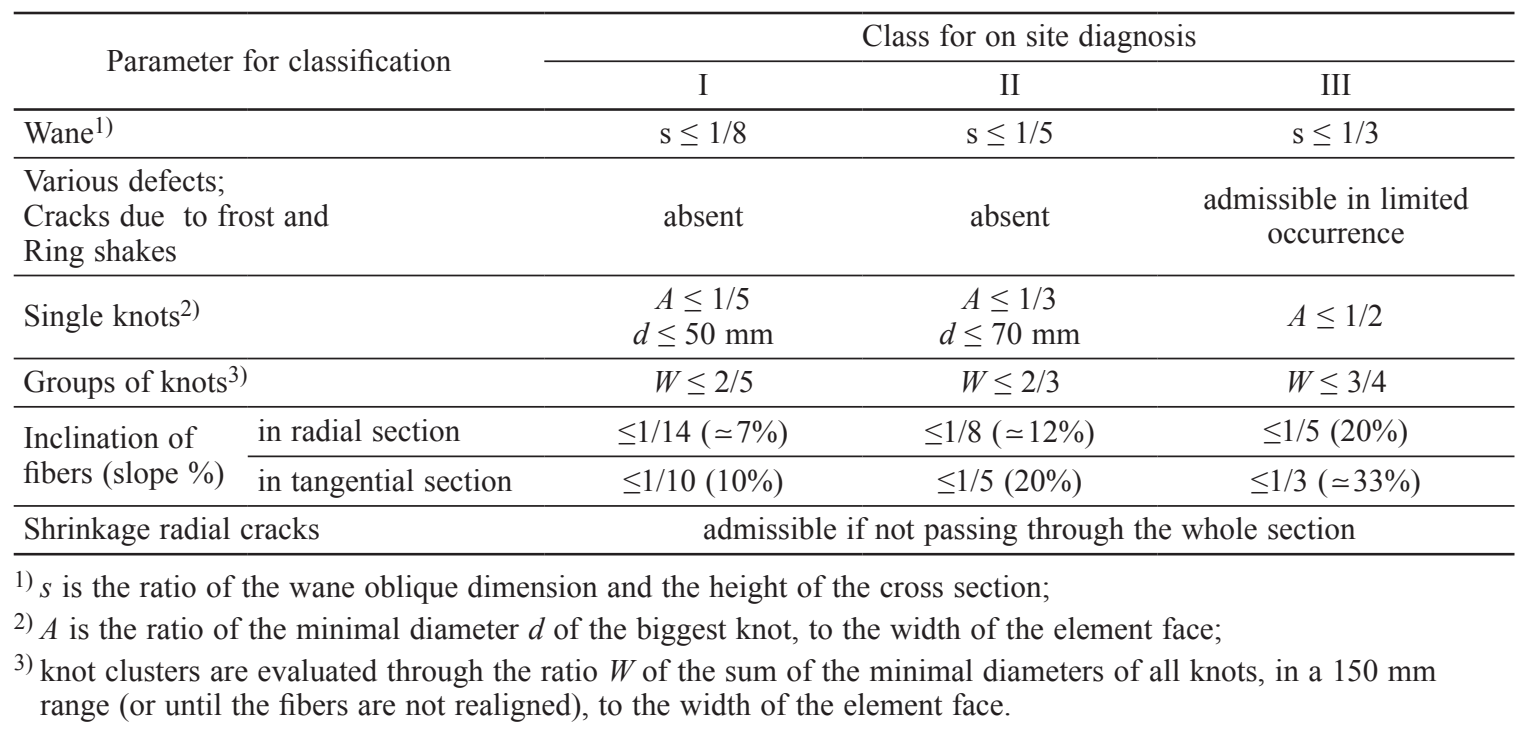


the $E_{\mathrm{m}, \mathrm{g}}$ also considers the presence of shear. The cross section dimensions and their relation to the length of the element lead to a minor influence of shear stress in the results. Also, as the shear modulus was not obtained experimentally, its value was assumed to be unknown and taken as infinite as suggested in EN 408:2010 (2010). Further discussion about 4-point bending tests is given in Brancheriau et al. (2002) while a comparison between $E_{\mathrm{m}, 1}$ and $E_{\mathrm{m}, \mathrm{g}}$ is addressed in Boström (1999) and Solli (2000).

In Phase 3, after the visual inspection and grading, timber sawn boards were subjected to bending tests in elastic regime according to EN 408:2010 (2010), although the height was chosen to be the smaller cross section dimension $(h=4 \mathrm{~cm})$ in order to establish a consistent measurement of the stiffness parameters, expressed by the bending MOE, with size variation. Aiming to analyze the bending $\mathrm{MOE}$ variation along the elements length, $E_{\mathrm{m}, 1}$ and $E_{\mathrm{m}, \mathrm{g}}$ were measured in the segments corresponding to those evaluated by visual inspection. Seven consecutive bending tests were made to each board, with supports placed in different locations. The tests were equally spaced and the assumed gauge lengths for the determination of MOE were centered with the visual inspection segments. In the case of the extremity segments, the center of the bending tests could not coincide with the center of the segments considered in the visual grading, as adequate support conditions would not be assured due to necessary length between support points. To provide adequate support conditions (at least $h / 2$ after supports), the center of the bending tests made to the extremity segments was moved $2 \mathrm{~cm}$ to the center of the board with reference to the center of the segments considered for the visual grading (Fig. 2).

\section{Result of the experimental tests}

\subsection{Phase 1}

For the analyzed beams in the original condition, the visual inspection undertaken pointed out that the more damaged zones and with higher level of defects were mainly concentrated in the extremities of the beams, where high decay due to xylophagous insects and cracks were detected, and/or in the middle span zones, where the limiting parameters were the size of knots, the reduction of cross section due to the existence of drying cracks or the combination of both. Along the length of the timber elements, the variation in amount and size of defects, anomalies and decay was well noticeable. Therefore, even if a section presents damage that may limit its structural behavior, other sections still presented a satisfactory condition. This situation is especially relevant for old structures where decay, either due to fungi or xylophagous insects, has locally damaged a part of the timber element. In order to have a qualitative comparison along the timber beams length but, also between different beams, the percentage of segments with a given visual class was accounted for each beam (Fig. 3). In Figure 3, beams with lower level of visible damage by biological decay (beams A, G, J and Q) have segments in lower visual classes (classes III and NC) corresponding to the extremities of the beams, however in some cases also presenting higher level visual grading (class II) for the segments in the central third of the beam. In the case of the most decayed beam (beam L), with damage visible along all its length, all segments were visual graded as $\mathrm{NC}$, due to the loss of effective cross section and poor visual aspect. The presence of cracks, as main limiting visual parameter, was especially relevant in beams $\mathrm{H}$, $\mathrm{K}$ and $\mathrm{O}$, where a large percentage of segments were deemed as class $\mathrm{NC}$, whereas less relevant cracks were observed in beams C, E, F, I and T.

The knot incidence (minimum knot diameter to depth/width ratio) and slope of grain were considered as the most important influencing parameters for the MOE, as assumed by Cavalli and Togni (2011), thus, the possibility to discard the parameters influenced by external damage due to structural or environmental causes (e.g. decay, deformation or cracks) was also considered. This allows to obtain the mechanical properties related to the material itself and its defects rather than to the state of conservation, which may be simulated by a re-

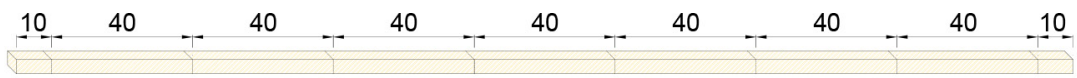

a)
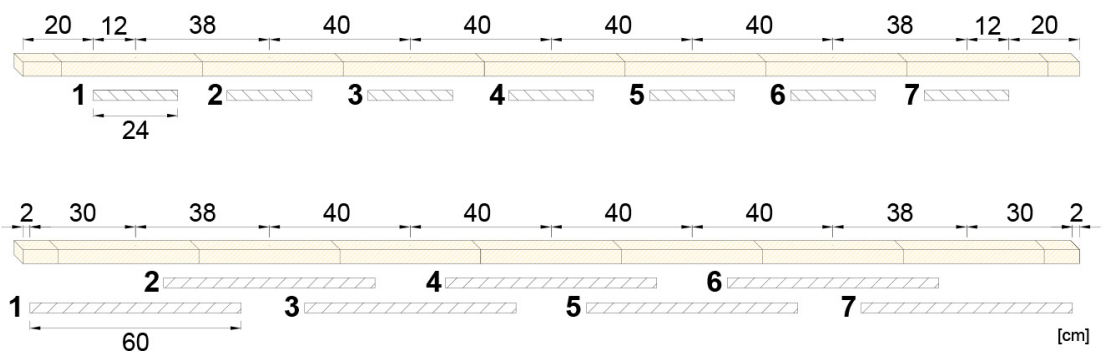

Fig. 2. Location for the sequential bending tests (dimensions in centimeters): a) visual inspection segments; b) gauge length for $E_{\mathrm{m}, \mathrm{l}}$ (in shade); c) gauge length for $E_{\mathrm{m}, \mathrm{g}}$ (in shade) 


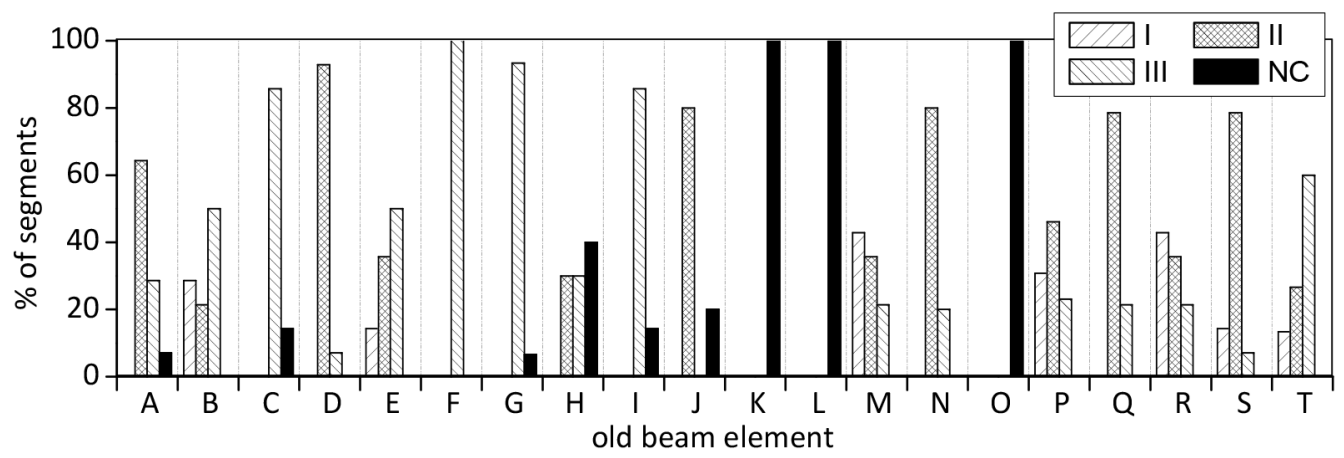

Fig. 3. Percentage distribution of segments in the old beams included in each visual grading class (UNI 11119:2004) considering damage due to external causes

duction of the effective cross section (Lourenço et al. 2013). Another purpose of the classification without the parameters of external damage is to obtain reference values for comparison with the smaller samples that will be taken in the following steps of the experimental campaign. The results are presented in Figure 4, which comparing to Figure 3, shows a decrease on the percentage of lower visual classes and an increase on the higher visual classes (especially class I). In this case, only beams $\mathrm{C}, \mathrm{G}$ and $\mathrm{L}$ have segments with grade $\mathrm{NC}$, resulting from the presence of significant knots. With exception of beam $\mathrm{G}$, a minimum percentage of $70 \%$ of the sum of classes I and II are found for each beam. By comparison to Figure 3, the results in Figure 4 evidence that the methodology of visual inspection should consid- er not solely the presence and extent of external damage (biological activity, cracks and wane) but also the resulting residual cross section, as these two approaches may lead to significant different visual grading for existing timber members.

\subsection{Phase 2}

Since the exterior signs of decay were removed during the sawing process, and only superficial cracks were present, exclusively knots (isolated and cluster) and alignment of fibers were considered as limiting parameters for the visual inspection. Figure 5 shows the percentage of segments included in each class of the visual inspection classification. Similar percentages of segments per class are observed between each old and

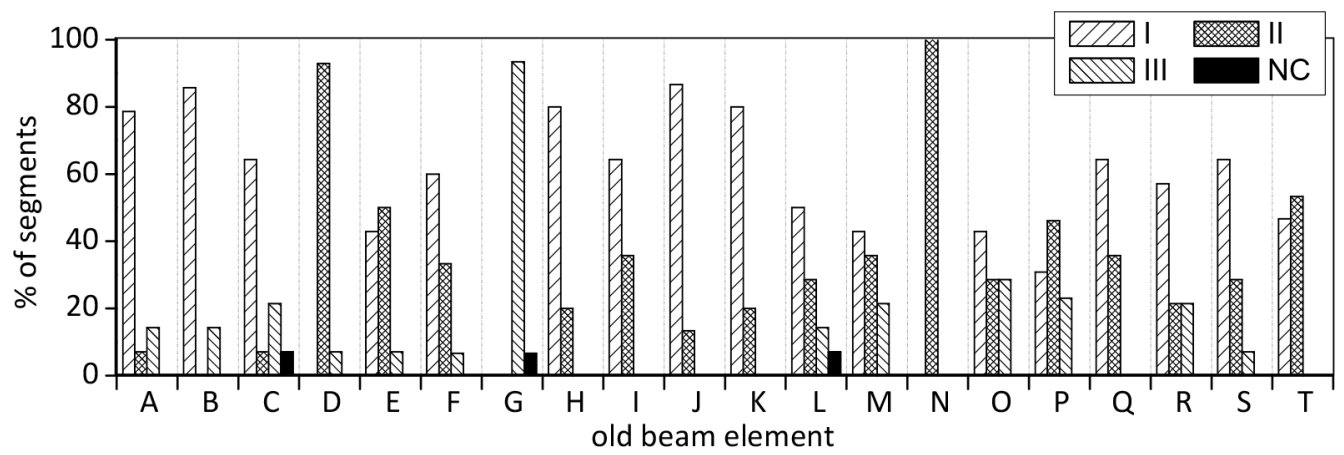

Fig. 4. Percentage distribution of segments in the old beams included in each visualgrading class (UNI 11119:2004) without considering damage due to external causes

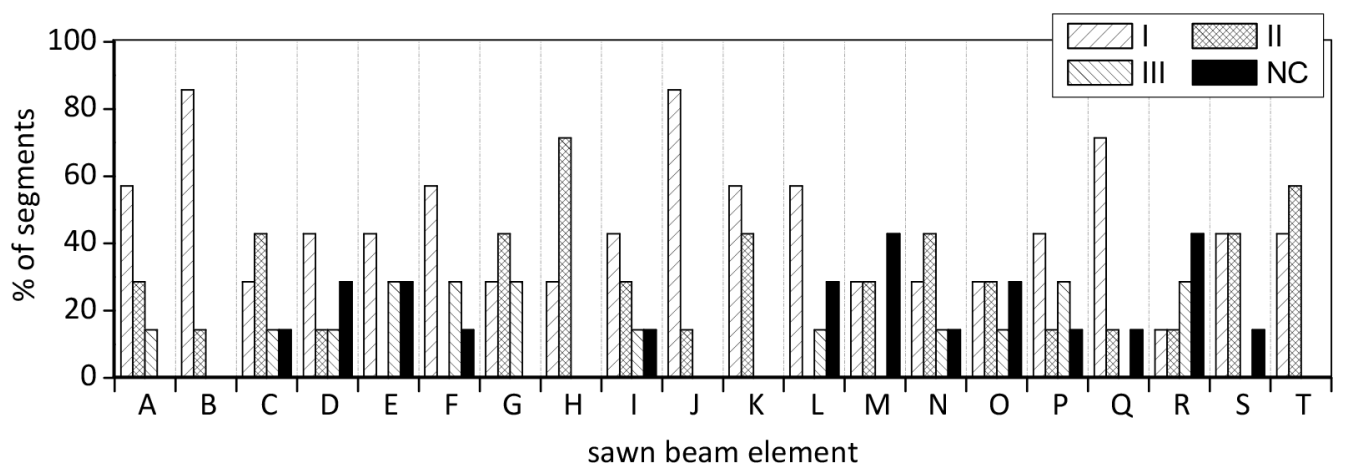

Fig. 5. Percentage distribution of segments included in each visual grading class according to UNI 11119:2004 for sawn beams 
sawn beam (comparison with Fig. 4), especially regarding the extreme classes (class I and NC). Accounting the different percentages of segments attributed to a given class for each beam between phases, it is noticed that in $60 \%$ of the cases, a difference lower than $15 \%$ is found between Phase 1 (Fig. 4) and Phase 2 (Fig. 5). On the other hand, $19 \%$ of the cases have a difference higher than $30 \%$. The mean difference between the same class in different phases is for class I of $19 \%$ and for class $\mathrm{NC}$ of $15 \%$. In a overall analysis, in $95 \%$ of cases Figure 5 presents higher or equal percentages of class NC than Figure 4 (the exception is beam G), indicating that a larger percentage of lower classes is observed in sawn beams due to the increase of the ratio $d / h$ (diameter of knots/cross section height) when reducing the cross section area of the elements. On the opposite side, Figure 5 presents higher percentages of class I than Figure 4, in $30 \%$ of the cases, corresponding to the situations where the defects that limited the visual grading in the previous phase were only superficial and were removed during the sawing process (beams D, G, L, N, P and Q). In these cases from Phase 1 to 2, a shift of percentage value from classes II and III to class I is noted.

The results of the bending tests are compiled in Figure 6 , where a mean value of $10840 \mathrm{~N} / \mathrm{mm}^{2}$ was found for $E_{\mathrm{m}, 1}$ and $10940 \mathrm{~N} / \mathrm{mm}^{2}$ for $E_{\mathrm{m}, \mathrm{g}}$ with $\mathrm{CoVs}$

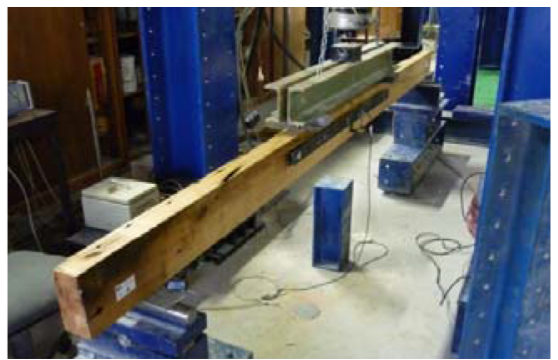

\begin{tabular}{ccc}
\hline & mean $\left[\mathrm{N} / \mathrm{mm}^{2}\right]$ & $\mathrm{CoV}[\%]$ \\
\hline$E_{\mathrm{m}, 1}$ & 10840 & 25.3 \\
$E_{\mathrm{m}, \mathrm{g}}$ & 10940 & 22.0 \\
\hline
\end{tabular}

a)

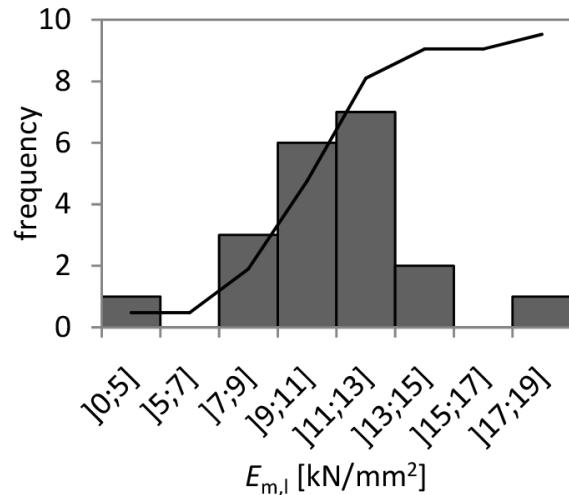

c) of about $25 \%$. This variation is higher than the $\mathrm{CoV}$ of $13 \%$ for the MOE suggested in the Probabilistic Model Code (JCSS 2006) for softwoods. A strong correlation is found between $E_{\mathrm{m}, 1}$ and $E_{\mathrm{m}, \mathrm{g}}\left(r^{2}=0.82\right)$ which maintains strong for the correlation with tendency line intercepting the origin with a $45^{\circ}$ angle $\left(r^{2}=0.76\right)$. More than $50 \%$ of the values of both MOE are distributed within the range $[9 ; 13] \mathrm{kN} / \mathrm{mm}^{2}$. Histograms and cumulative distribution functions are also plotted (Figs $6 \mathrm{c}$ and $6 \mathrm{~d}$ ).

The old beams with at least $20 \%$ in lower classes (III and NC) in the visual inspection (Fig. 4), resulted in sawn beams with $E_{\mathrm{m}, \mathrm{g}}$ values lower than the mean, while old beams with higher percentage of class I and II (higher than $80 \%$ ) originated sawn beams with higher values of $E_{\mathrm{m}, \mathrm{g}}$. However, in the cases of beams D, E and F, although with only $7 \%$ of lower visual classes, the value of $E_{\mathrm{m}, \mathrm{g}}$ was lower than the mean. In these cases, the critical sections were located in the central third of the span and were more influencing for the results, in accordance with the consideration of a critical section for determination of the global characteristics. The exceptions to these premises were beams $\mathrm{H}$ and $\mathrm{T}$, which although not evidencing any lower class percentage in visual grading, also evidenced lower $E_{\mathrm{m}, \mathrm{g}}$ values than the mean. The mean value of $E_{\mathrm{m}, 1}$ is similar to the value given for class I in UNI 11119:2004 (2004) $\left(10000 \mathrm{~N} / \mathrm{mm}^{2}\right)$. This indicates that clear wood elements for these particu-

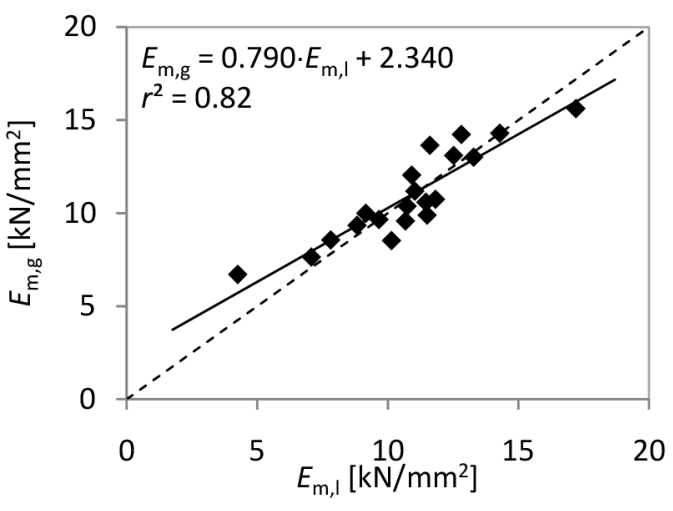

b)
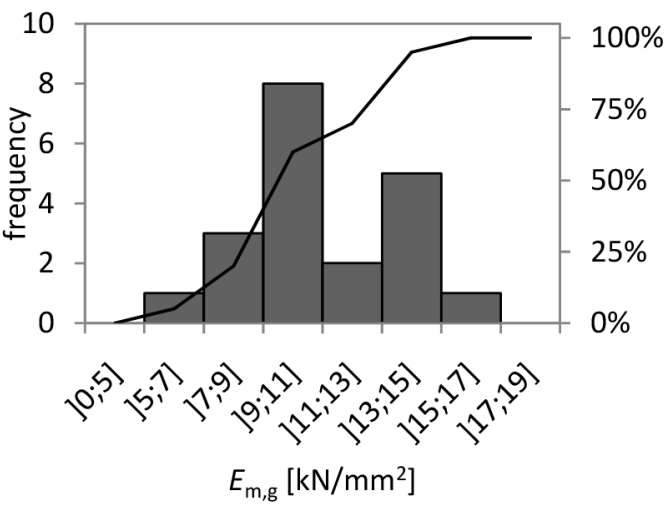

d)

Fig. 6. Sawn beams bending tests in elastic regime: a) test set-up and results; b) correlation between $E_{\mathrm{m}, 1}$ and $E_{\mathrm{m}, \mathrm{g}}$; c) histogram and cumulative distribution function for $E_{\mathrm{m}, 1} ; \mathrm{d}$ ) histogram and cumulative distribution function for $E_{\mathrm{m}, \mathrm{g}}$ 
lar beams have much higher values than those indicated in the norm for class I.

\subsection{Phase 3}

In Phase 3, each beam was sawn in three boards (except beams $\mathrm{H}, \mathrm{L}, \mathrm{P}$ and $\mathrm{T}$ that were tested until failure in the previous phase), being the top, middle and bottom boards numbered as $\mathrm{X} 1, \mathrm{X} 2$ and $\mathrm{X} 3$, respectively (with $\mathrm{X}$ being the identification of the original beam). During visual inspection, the sawn boards segments were numbered from 1 to 7 from left to right. For this case, Figure 7 presents the percentage of segments included in each class of the visual grading.
The results of the bending tests are compiled in Figure 8, where a mean value of $12190 \mathrm{~N} / \mathrm{mm}^{2}$ was found for $E_{\mathrm{m}, 1}$ and $11660 \mathrm{~N} / \mathrm{mm}^{2}$ for $E_{\mathrm{m}, \mathrm{g}}$ with CoVs of about $25 \%$. The values given by segments for a given beam were averaged and a strong correlation is found between $E_{\mathrm{m}, 1}$ and $E_{\mathrm{m}, \mathrm{g}}\left(r^{2}=0.89\right)$. More than $50 \%$ of the values of both MOEs are distributed within the range $[10 ; 16] \mathrm{kN} / \mathrm{mm}^{2}$, as shown by histograms and cumulative distribution functions in Figures $8 \mathrm{c}$ and $8 \mathrm{~d}$. The results revealed that bending MOE vary in different proportions in height and length, with higher variation when a larger concentration of knots was found in a board. The mean CoV for the same segment of a set of boards (e.g. measurements

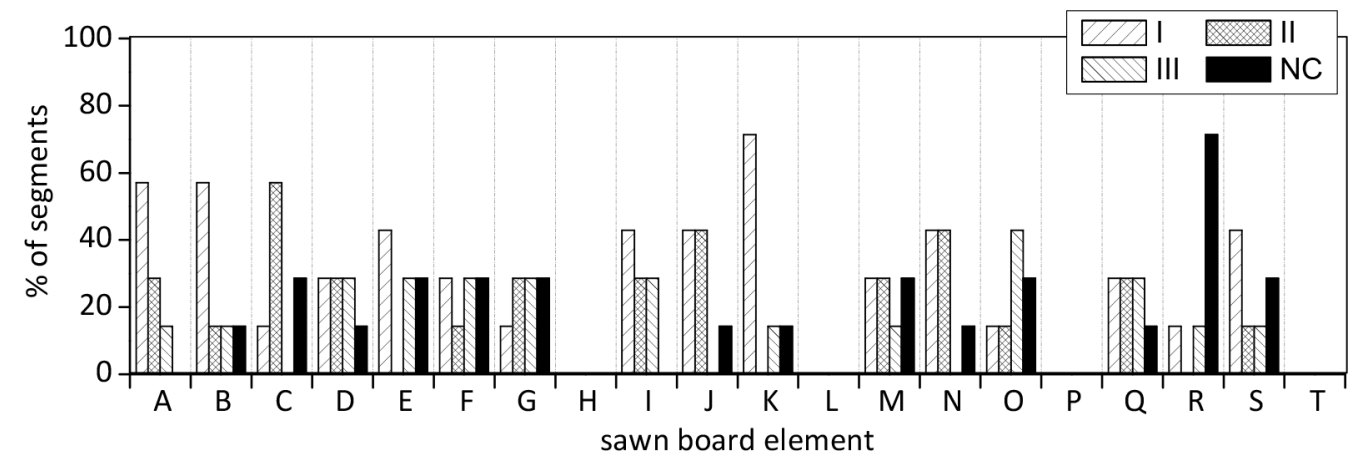

Fig. 7. Percentage distribution of segments included in each visual grading class according to UNI 11119:2004 for sawn boards (beams H, L, P and T were tested until failure in Phase 2)
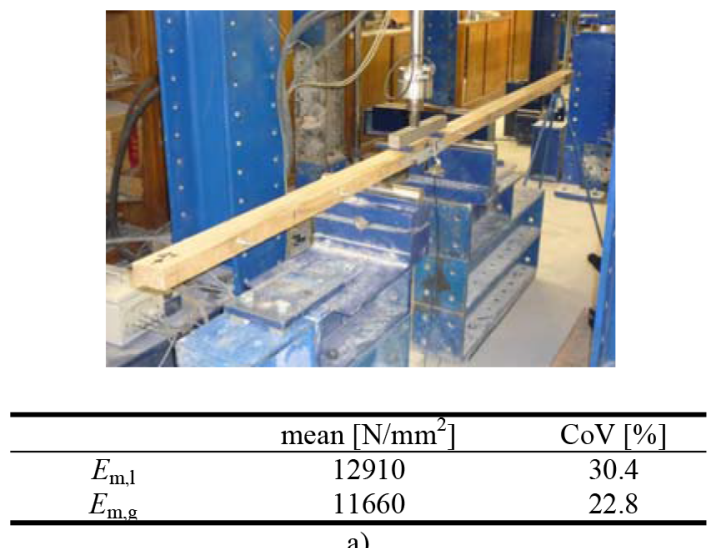

a)

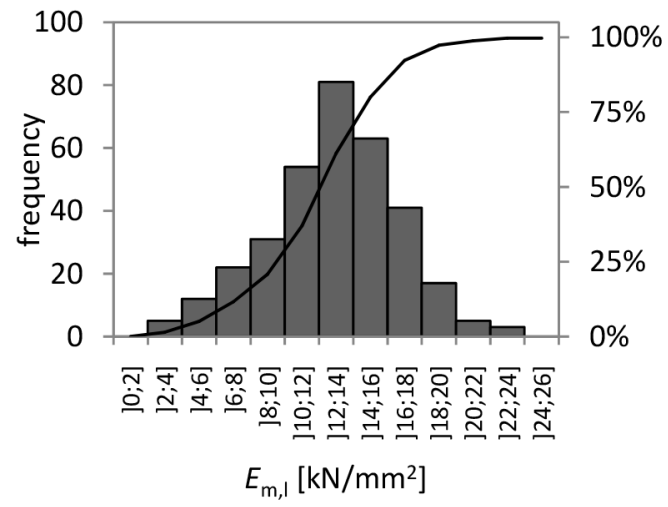

c)

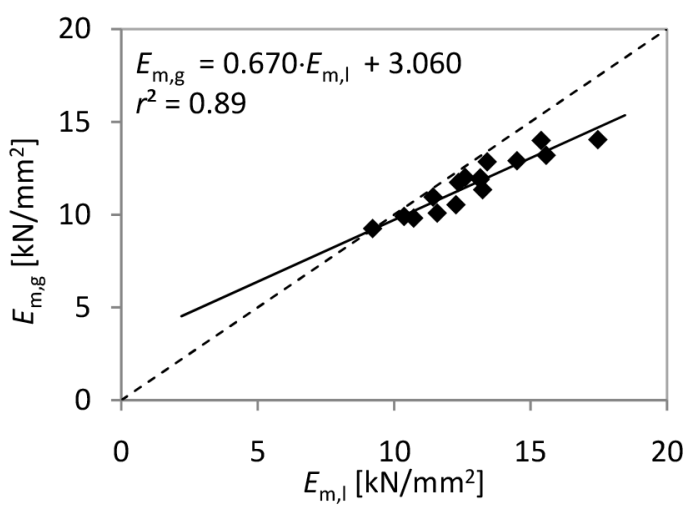

b)

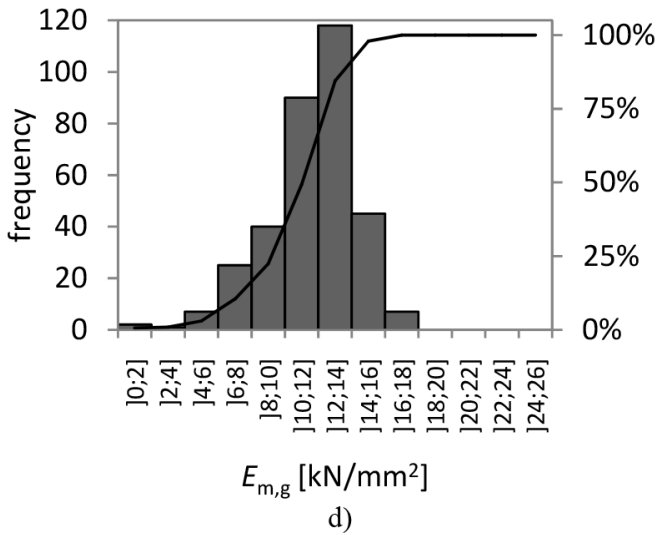

d)

Fig. 8. Sawn boards bending tests in elastic regime: a) test set-up and results; b) correlation between $E_{\mathrm{m}, 1}$ and $E_{\mathrm{m}, \mathrm{g}}$; c) histogram and cumulative distribution function for $\left.E_{\mathrm{m}, 1} ; \mathrm{d}\right)$ histogram and cumulative distribution function for $E_{\mathrm{m}, \mathrm{g}}$ 
along the height in A1, A2 and A3 for segments 1) is equal to $20.1 \%$ and $15.7 \%$, respectively for $E_{\mathrm{m}, 1}$ and $E_{\mathrm{m}, \mathrm{g}}$, whereas the mean $\mathrm{CoV}$ for all segments of a given board (e.g. measurements in A1 along the length for segments 1 to 7 ) is slightly higher being equal to $25.8 \%$ and $17.9 \%$, respectively, for $E_{\mathrm{m}, 1}$ and $E_{\mathrm{m}, \mathrm{g}}$.

Aiming to assess the correlation between results obtained in Phase 3, an analysis of variance (ANOVA) was made regarding the parameters $E_{\mathrm{m}, 1}$ and $E_{\mathrm{m}, \mathrm{g}}$ with respect to the visual grading. In this case, ANOVA was used to test whether visual strength grading contributes significantly to the variation in bending MOE. In this case, for $E_{\mathrm{m}, 1}$ and $E_{\mathrm{m}, \mathrm{g}}$, a single-factor ANOVA and a confidence level of $95 \%$ revealed a significant variance in bending MOE between the different considered visual strength classes $\left(F>F_{\text {crit }}\right.$ and $p$ value $\left.<0.05\right)$, see Table 2. Therefore, it is demonstrated that the partition of the results of bending MOE with consideration to the visual strength classes allows obtaining sam-

Table 2. Single-factor ANOVA results for parameters $E_{\mathrm{m}, 1}$ and $E_{\mathrm{m}, \mathrm{g}}$ with respect to different visual strength classes

\begin{tabular}{cccc}
\hline Parameter & $\mathrm{F}$ & $F_{\text {crit }}$ & $\mathrm{p}$-value \\
\hline$E_{\mathrm{m}, \mathrm{l}}$ & 13.212 & 2.639 & $4.67 \times 10^{-8}$ \\
\hline$E_{\mathrm{m}, \mathrm{g}}$ & 25.644 & 2.639 & $1.43 \times 10^{-14}$ \\
\hline
\end{tabular}
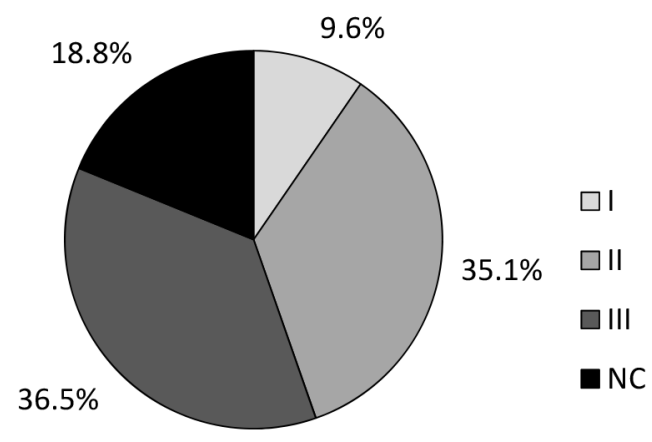

a)

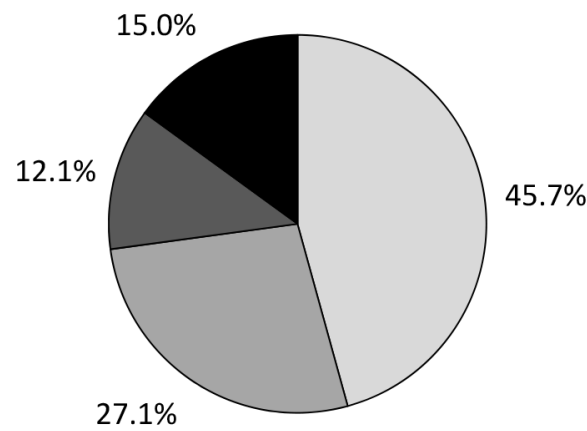

c) ples with significant statistic variation values between them, evidencing different clusters of measurements. Accounting this premise, visual inspection grading may be used as an indicator to distinguish segments with different bending MOE results within a same timber member.

\subsection{Correlations between testing phases}

Visual inspection evidenced different percentages of segments included in a visual grade for the separate testing phases (Fig. 9). In Phase 1, for old beams with consideration of damage due to external causes, the average of segments in a visual grade is $9.6 \%$ for I, $35.1 \%$ for II, $36.5 \%$ for III and $18.8 \%$ for NC. Also in Phase 1, the expected outcome of omitting the damage due to external causes was the increase of percentage in higher classes. A decrease of NC segments percentage was found. These results are more relevant to the beams presenting widely spread decay. For the entire sample, the average of segments in each visual grading class is $52.0 \%$ for I, $32.1 \%$ for II, $14.8 \%$ for III and $1.1 \%$ for $\mathrm{NC}$.

In Phase 2, visual grading indicates an increase of the average percentage of segments for $\mathrm{NC}$ and a decrease for class I. A decrease in the average $\mathrm{CoV}$ of the percentage of a given visual class between different members is also found. The average of segments in each

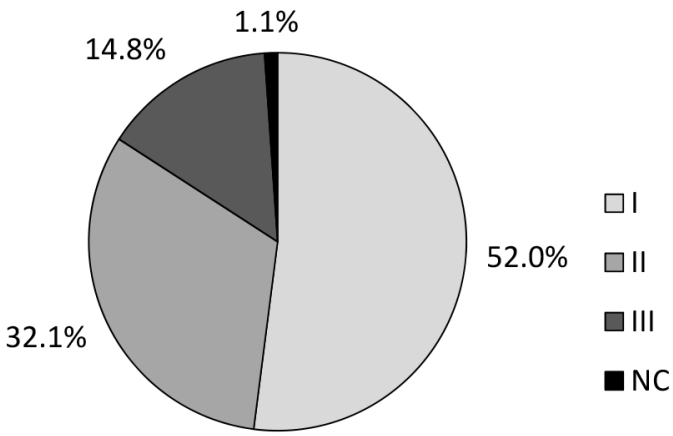

b)

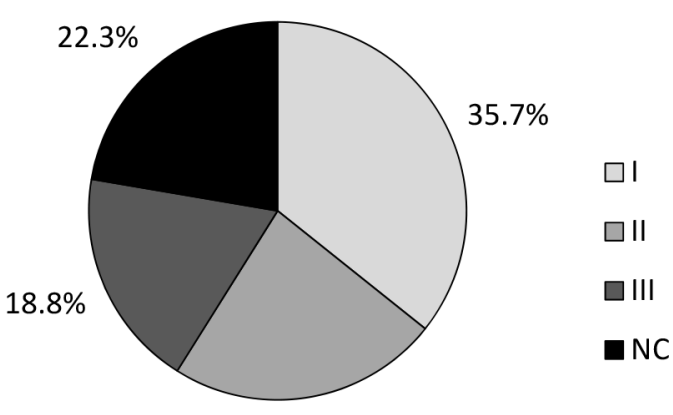

$23.2 \%$

d)

Fig. 9. Percentage distribution of segments included in each visual grading class according to UNI 11119:2004 for the entire sample: a) old beams considering damage due to external causes; b) old beams without considering damage due to external causes; c) sawn beams; d) sawn boards 
visual grading class is $45.7 \%$ for I, $27.1 \%$ for II, $12.1 \%$ for III and $15.0 \%$ for NC.

In Phase 3, the average of segments in a visual grading class is $35.7 \%$ for I, $23.2 \%$ for II, $18.8 \%$ for III and $22.3 \%$ for NC. Similar percentages per class are observed between each sawn beam and sawn board. However, a larger percentage of lower classes is observed in some boards due to the increase of the ratio $d / h$ (diameter of knots/cross section height) when reducing the height of the elements. Visual grading often leads to a large percentage of rejection of the analyzed samples, depending on the considered restricting parameters. As an example, in Almazán et al. (2008), the consideration of two visual grading standards resulted, for the same sample, in either $5 \%$ or $40 \%$ of rejected pieces. A slight dependency was noted between piece slenderness and the kind of knot, which determines the grading.

The mean values of sawn boards bending tests are higher than the equivalent values obtained for sawn beams. As mentioned by Kasal and Anthony (2004), the timber member mechanical properties will always be lower than those of small clear specimens because of the inevitable presence of defects in structural size pieces. When the specimen size increases also the stressed volume increases and for brittle materials or systems organized in series, a higher probability that a weak link occurs in the volume exists (Weibull 1939).

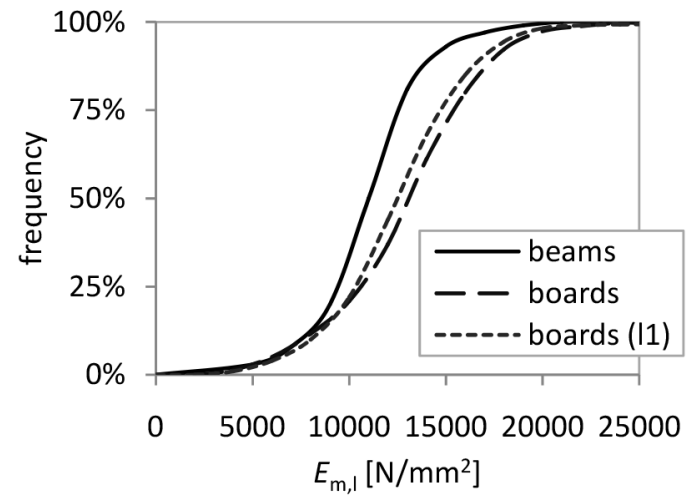

a)

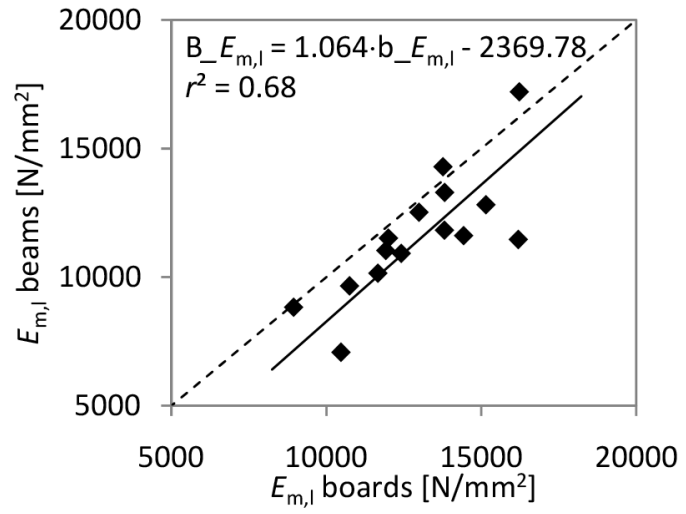

c)
The biggest difference is in $E_{\mathrm{m}, 1}$, with larger $\mathrm{CoV}$ in the case of the sawn boards. This is an expectable result since the gauge length for the determination of $E_{\mathrm{m}, \mathrm{g}}$ in sawn beams included the gauge length of $E_{\mathrm{m}, \mathrm{g}}$ in sawn boards, whereas the gauge length for $E_{\mathrm{m}, 1}$ of the sawn beams only considers segments 3,4 and 5 of sawn boards. Considering the mean value for those segments only, a $E_{\mathrm{m}, 1}$ of $12720 \mathrm{MPa}$ is obtained which is slightly closer to $E_{\mathrm{m}, 1}$ for sawn beams $(10840 \mathrm{MPa})$. Nevertheless, the values of bending MOE for sawn boards are still $18 \%$ and $7 \%$ higher, respectively, $E_{\mathrm{m}, 1}$ and $E_{\mathrm{m}, \mathrm{g}}$, than for sawn beams. This increase may be explained due to the decrease in influence of defects in the global behaviour when the beam was divided into boards, resulting also in a higher $\mathrm{CoV}$ due to the higher difference obtained between segments with and without defects. By isolating the effect of knots, timber mechanical properties will improve, as for example in the case of glulam beams which have better performance comparing to solid members of the same quality (Baltrušaitis 1999).

The cumulative distribution function of MOE given by the bending tests of beams and boards are given in Figure 10. Moderately strong correlations were found between the results of Phase 2 and 3, which deviate from the $45^{\circ}$ line, with similar coefficients of determination for $E_{\mathrm{m}, \mathrm{g}}$ and $E_{\mathrm{m}, 1}\left(r^{2}=0.71\right.$ and 0.68$)$. A better approximation is obtained for the $E_{\mathrm{m}, 1}$ correlation when considering only

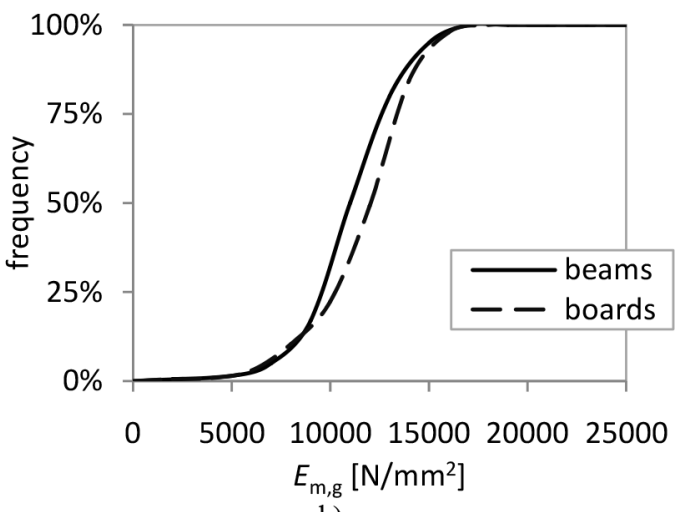

b)

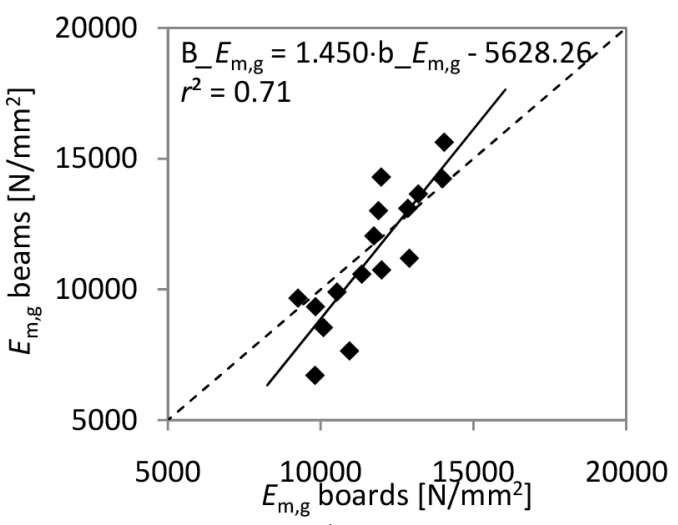

d)

Fig. 10. Correlation between bending tests in phase 2 and 3: a) cumulative distribution functions for $E_{\mathrm{m}, 1}$ (boards $l_{1}=$ segments of sawn boards in the $l_{1}$ length of the beams according to EN 408:2003); b) cumulative distribution functions for $E_{\mathrm{m}, \mathrm{g}}$; c) correlation between $E_{\mathrm{m}, 1} ; \mathrm{d}$ ) correlation between $E_{\mathrm{m}, \mathrm{g}}$ 
the segments of the boards comprehended by the sawn beams $l_{1}$ length (segments 3 to 5 ) per mean group of boards $\left(r^{2}=0.68\right.$ instead of 0.54$)$.

Density and moisture content were also determined, according to ISO 3130:1975 (1975) and ISO 3131:1975 (1975), using three samples from each beam. After stabilized (in climatic chamber under conditions of $20{ }^{\circ} \mathrm{C}$ and $59.6 \%$ $\mathrm{RH})$, a mean value of density equal to $519 \mathrm{~kg} / \mathrm{m}^{3}$ was obtained with $\mathrm{CoV}$ of $7.9 \%$ for all sample and $5.5 \%$ within beams, whereas a mean value of $12.2 \%$ was determined for moisture content with $\mathrm{CoV}$ of $8.1 \%$ for all sample and $3.8 \%$ within beams.

\section{Conclusions}

With aim at the definition of correlations between bending MOE in different scales sizes, in the presented multi-scale experimental campaign, it was concluded that visual inspection by segments may reveal large variability in the properties of existing timber elements along its length. Also, the consideration of knot incidence and slope of grain as main features lead to comparable results between experimental phases, although an increase of lower visual class percentage per element was found due to the increase of the ratio between the size of defects and the cross section dimensions. Visual inspection was accurate for predicting qualitatively the performance of the timber elements, since the elements with larger percentage of lower grade timber exhibit lower values of bending MOE, despite the fact that it proved to be conservative for elements with higher grade class percentages. Nevertheless, it was found that for local $E_{\mathrm{m}, 1}$ and global $E_{\mathrm{m}, \mathrm{g}}$ modulus of elasticity there is a significant variance in the results between samples of different visual strength classes. The old beams with at least $20 \%$ in lower classes in the visual inspection, resulted in the sawn beams with $E_{\mathrm{m}, \mathrm{g}}$ values lower than the mean, while old beams with more than $80 \%$ of percentage in higher visual classes originated sawn beams with higher values of $E_{\mathrm{m}, \mathrm{g}}$. However, when the lower class segments were located in the central third of the span, low $E_{\mathrm{m}, \mathrm{g}}$ were also found, evidencing that the presence of low class segments should also be taken into account with respect to their location.

The bending test results revealed that the bending MOE vary both in height and length of each beam in different proportions, being the variation higher when a larger concentration of knots was found in one of the boards. For this sample, the variation in length was found to be slightly higher than the variation in height. Strong correlations between $E_{\mathrm{m}, 1}$ and $E_{\mathrm{m}, \mathrm{g}}$ were found within the same experimental phase $\left(r^{2}=0.82\right.$ in sawn beams and $r^{2}=0.89$ in sawn boards). Moderate to high correlations between $E_{\mathrm{m}, 1}$ and $E_{\mathrm{m}, \mathrm{g}}$ for different experimental phases $\left(r^{2}=0.68\right.$ and 0.71 , respectively) were found, with the cumulative distribution function of $E_{\mathrm{m}, \mathrm{g}}$ being similar in the different test campaign phases. The mean values of sawn boards bending tests were $18 \%$ and $7 \%$ higher than the equivalent values obtained for sawn beams, respectively for $E_{\mathrm{m}, 1}$ and $E_{\mathrm{m}, \mathrm{g}}$.
The present work provides a contribution to the increase of knowledge in the characterization of bending MOE in different scales sizes of old timber members. The presented results evidenced strong correlations between different phases of the experimental campaign, and therefore, confirmed the possibility to combine bending tests with visual inspection for the analysis of bending MOE from smaller scale specimens to structural size timber elements.

\section{Acknowledgements}

The financial support of the Portuguese Science Foundation (Fundação para a Ciência e a Tecnologia, FCT), through $\mathrm{PhD}$ Grant SFRH/BD/62326/2009, is gratefully acknowledged. The authors acknowledge also the support of Augusto de Oliveira Ferreira e Companhia Lda. (offer of specimens) and of the Structural Lab from University of Minho (test facilities).

\section{References}

Almazán, F. J. A.; Prieto, E. H.; Martitegui, F. A.; Richter, C. 2008. Comparison of the Spanish visual strength grading standard for structural sawn timber (UNE 56544) with the German one (DIN 4074) for Scots pine (Pinus sylvestris L.) from Germany, Holz als Roh- und Werkstoff 66(4): 253-258. http://dx.doi.org/10.1007/s00107-008-0241-9

Baltrušaitis, A. 1999. Estimation of strength of glulam beams depending on defect of layers, Statyba 5(4): 245-249 (in Lithuanian).

http://dx.doi.org/10.1080/13921525.1999.10531471

Boström, L. 1999. Determination of the modulus of elasticity in bending of structural timber - comparison of two methods, European Journal of Wood and Wood Products 57(2): 145-149.

http://dx.doi.org/10.1007/s001070050030

Brancheriau, L.; Bailleres, H.; Guitard, D. 2002. Comparison between modulus of elasticity values calculated using 3 and 4 point bending tests on wooden samples, Wood Science Technology 36(5): 367-383. http://dx.doi.org/10.1007/s00226-002-0147-3

Branco, J. M.; Piazza, M.; Cruz P. J. S. 2010. Structural analysis of two King-post timber trusses: non-destructive evaluation and load-carrying tests, Construction and Building Materials 24(3): 371-383. http://dx.doi.org/10.1016/j.conbuildmat.2009.08.025

Burley, J.; Evans, J.; Younquist, J. (Eds.). 2004. Mechanical properties of wood, in Encyclopedia of forest science. Oxford: Elsevier Publishing Co, 1815-1828.

Cavalli, A.; Togni, M. 2011. Combining NDT and visual strength grading to assess ancient timber beams stiffness to evaluate strengthening interventions suitability, in Proc. of the $17^{\text {th }}$ International Nondestructive Testing and Evaluation of Wood Symposium, 14-16 September 2011, Hungary, 593-601.

EN 14081-1:2005 Timber Structures - Strength graded structural timber with rectangular cross section - Part 1: General requirements. European Committee for Standardization, 2005.

EN 1912:2012 Structural timber. Strength classes. Assignment of visual grades and species. European Committee for Standardization, 2012. $22 \mathrm{p}$.

EN 408:2010 Timber structures - Structural timber and glued laminated timber - Determination of some physical and mechanical properties. European Committee for Standardization, 2010. 
EN 518:1997 Structural Timber - Grading - Requirements for Visual Strength Grading Standards. European Committee for Standardization, 1997.

Gloss, P. 1986. Ermittlung der nationalen und internationalen Standes des maschinellen Holzsortierung. München: Deutsche Gesellschaft fur Holzforschung, Final report, Research Project BOS021D(B) (in German).

Huber, H. A.; McMillin, C. W.; McKinney, J. P. 1985. Lumber defect detection abilities of furniture rough mill employees, Forest Products Journal 35(11/12): 79-82.

ISO 3130:1975 Wood-Determination of moisture content for physical and mechanical tests. International Organization for Standardization, 1975.

ISO 3131:1975 Wood-Determination of density for physical and mechanical tests. International Organization for Standardization, 1975.

JCSS. 2006. JCSS Probabilistic Model Code, Part 3: Resistance Models - 3.5 Properties of Timber, in Probabilistic Model Code. Joint Committee on Structural Safety.

Kasal, B. (Ed.). 2010. State-of-the-art in in-situ assessment of timber, in RILEM TC AST 215 Special Publication. Springer Verlag/RILEM Paris.

Kasal, B.; Anthony, R.W. 2004. Advances in in situ evaluation of timber structures, Progress in Structural Engineering and Materials 6(2): 94-103. http://dx.doi.org/10.1002/pse.170

Lourenço, P. B.; Sousa, H. S.; Brites, R. D.; Neves, L. C. 2013. In situ measured cross section geometry of old timber structures and its influence on structural safety, Materials and Structures 46(7): 1193-1208.

http://dx.doi.org/10.1617/S11527-012-9964-5

Muñoz, G. R.; Gete, A. R.; Saavedra, F. P. 2011. Implications in the design of a method for visual grading and mechanical testing of hardwood structural timber for assignation within the European strength classes, Forest Systems INIA 20(2): 235-244. http://dx.doi.org/10.5424/fs/2011202-9771

Solli, K. H. 2000. Modulus of elasticity - local or global values, in Proc. of the $6^{\text {th }}$ World Conference on Timber Engineering, 31 July - 3 August 2000, Whistler, British Columbia, Canada.

Teder, M.; Pilt, K.; Miljan, M.; Pallav, V.; Miljan, J. 2012. Investigation of the physical-mechanical properties of timber using ultrasound examination, Journal of Civil Engineering and Management 18(6): 795-801. http://dx.doi.org/10.3846/13923730.2012.736233

Thelandersson, S.; Larsen, H. J. 2003. Timber engineering. Chichester: John Wiley \& Sons Ltd. 446 p.

UNI 11119:2004 Cultural heritage-wooden artifacts-loadbearing structures-on site inspections for the diagnosis of timber members. Ente Nazionale Italiano di Unificazione, Milano, 2004. 9 p. (in Italian).

Weibull, W. 1939. A statistical theory of the strength of materials, in Proc. of the Royal Swedish Institute of Engineering Research, 1939, Stockholm, Sweden, N.151.

Hélder S. SOUSA. PhD student, Invited Assistant, member of the Institute for Sustainability and Innovation in Structural Engineering, Civil Engineering Department, University of Minho. Research interests: timber structures, structural safety assessment, reliability methods and non-destructive testing.

Jorge M. BRANCO. PhD, Assistant Professor, member of the Institute for Sustainability and Innovation in Structural Engineering, Civil Engineering Department, University of Minho. Research interests: wood based materials, timber structures and sustainable building.

Paulo B. LOURENÇO. PhD, Professor, Head of the Institute for Sustainability and Innovation in Structural Engineering. Head of the Structural Engineering Group in the Civil Engineering Department, University of Minho. Coordinator of the European Erasmus Mundus Advanced Masters in Structural Analysis of Monuments and Historical Constructions. He is a specialist in historical structures. Research interests: NDT, advanced experimental and numerical techniques, innovative strengthening techniques and earthquake engineering. 